\title{
Genre, Methodology and Feminist Practice
}

Gladys Reichard's ethnographic voice

\section{Lessie Jo Frazier}

University of Michigan

The rainy season is not quite over although it has nearly spent itself. I drive leisurely along five miles of roller coaster highway, down and up, up and down again as I drink in the grandeur of the sunset. I come to the 'big hill', around and over which the road twines narrowly. From its summit I see at my left a deep purple canyon, green at the bottom with irrigated fields. At my right the sun is setting across a wide valley, the shadows replaced by roseate gold interrupted by the white resplendence of chalk cliffs. As if this were not sufficient, a light female rain like that which falls constantly over the home of the Corn gods, drops between me and the sun. I gasp in my inability to comprehend the sight fully as I turn my head forty-five degrees to behold a complete rainbow and behind it the thinnest slice of a new moon. (Gladys Reichard, 1934: 122)

\section{Introduction: approaches and themes}

In this essay, I read and discuss Gladys Reichard as an author of feminist ethnography - not in order to define or bound her place in anthropology, but rather to attempt to approach her work from a particular, critical perspective. In this effort I concentrate on two of Reichard's most accessible and popular works of the 1930s, Spider Woman: A Story of Navajo Weavers and Chanters (1934) and Dezba, Woman of the Desert (1939). Through an examination of Reichard's work, I discuss the relationship between issues of genre, methodology (see Harding, 1987) and ethnography as feminist practice. While the role of fieldwork in the text has often been discussed, few critics have considered the importance of reading ethnography for an understanding of methodology. By methodology, I mean a theory of research, methods and representation embodied in ethnographic practice. Reading ethnography for methodology allows us

Critique of Anthropology (C) 1993 (SAGE, London, Newbury Park and New Delhi), Vol. 13(4): 363-378. 
to explore the relationship between field and text as they become enveloped in the process of anthropological scholarship.

In her writing, Reichard elegantly evokes the glory and grandeur of the Southwest as well as her own love of this region. Throughout her work, Reichard incorporates evocative images of landscape, events and personalities:

This house bulges with life. Bursting sacks of wool hanging from its sides. Long, clean, brightly colored skeins of spun yarn hang from the beams and loom posts. The box on the floor at the woman's side has strands of pink and red, orange and green, brown, gray and black yarn fringing its edges. Each one holds itself in readiness to be pulled by its mistress' skillful fingers. A cat rubs our legs, by way of investigative greeting, and returns to her litter of kittens behind the loom.... The woman interrupts her weaving long enough to turn on me a gleaming smile and to indicate a strong low box on which I, being a stranger, may sit. As we talk and smoke, the woman weaves, her swiftly moving fingers causing the blanket to grow visibly. As I watch, I am consumed with envy mingled with admiration, for this is what I have come to learn. (Reichard, 1934:3)

Reichard begins Spider Woman with this scene of arrival in which she evokes a sense of place while keeping herself fully within the frame of reference though not the center of attention. ${ }^{1}$ Rather than creating a romanticizing sense of an idyllic harmony between humans and nature, Reichard fills her descriptions of Navajo homes and stunning Southwestern landscapes with human beings, including herself, working and celebrating, living and dying.

Yet over the course of Reichard's career, her writing undergoes dramatic shifts in form and style. I posit that shifts in style and voice from one work to the next indicate a scholar struggling to forge a place, though not necessarily a voice, for herself at a particular moment in the history of anthropology. Others have written on the topic of Reichard and the gendered politics of anthropology (Lamphere, 1992; Lyon, 1989: 3). I will refer to those debates to the extent that they can inform and be informed by a reading of Reichard as a woman writing culture. It is important to keep in mind that in the early years of American anthropology, the form that ethnography would take remained an open question. Furthermore, Gladys Reichard exemplifies the ways in which students of Franz Boas - such as Zora Neale Hurston, Ruth Benedict, Edward Sapir, Margaret Mead and Ella Deloria - explored a wide spectrum of modes of representation, including encyclopedic studies, dry field reports, poetry, film, photography, novels, plays, collections of texts, popular magazine articles and ethnographies. $^{2}$ 
In this essay, I give special weight to Spider Woman. This book represents a moment in Reichard's career in which she is most able, or free, to integrate herself into both the process and product of ethnography. Thus, I examine her work by first tracing the shifts in genre and authorial voice as Reichard moves through her career. Then, I examine the notion that it was her innovative methodology which helped to create the moment out of which Spider Woman emerges. In this work, Reichard integrates her appreciation for the aesthetic and spiritual richness of Navajo culture with her own growth as a scholar by exploring and testing the limits of cross-cultural learning. Early on in her fieldwork, as Reichard begins to settle in, she tells us:

The sun, by its death bringing the earth to life, lures me outside. I expect at any moment the bark of an oncoming dog. . . . But there is not a sound. The glow is with me, it brings the sage and sand into a gentle radiance, but there are no woolly pelts to reflect its splendor, no scarlet shirts to cast it back into itself. A bluebird chirps to his mate in the branches of my pinon, a turtledove cries mournfully near Maria Atlnaba's shade. I still expect my family, and after dark lay out my bed under the Great Dipper. . . This is limbo. A perfect place where for me the gods are not. I am not lonesome, I am only alone. They must be here but I have not yet earned the right to say:

Holy Young Woman sought the gods and found them

On the summits of the clouds; she sought the gods and found them.

Truly with my sacrifice she sought the gods and found them.

Somebody doubts it, so I have heard.

It is quiet, too quiet. . . (Reichard 1934: 125)

\section{Shifting genres}

Gladys Reichard, a physician's daughter, was born in 1893 in Pennsylvania. She grew up in a Quaker household and taught school for many years before earning her college degree from Swarthmore. In 1919, Reichard received the Lucretia Mott Fellowship and entered the graduate anthropology program at Columbia University. Gladys Reichard emerges from a generation of remarkable women anthropologists who studied at Columbia. She benefitted from the mentorship of Elsie Clews Parsons and Franz Boas. Reichard strongly maintained many of the basic Boasian tenets. She held to a holistic view of culture, was concerned with cultural survival, was carefully trained in linguistics, and often worked within a rigorous comparative method. Reichard's first monograph was an encyclopedic work on the social life of the Navajo (1928) that impressed Boas enough for him to secure a position for Reichard at Barnard College. She 
was the first of Boas's female students to gain such a position and this generated a great deal of tension between Reichard and the other women. ${ }^{3}$

In 1930, Reichard began intensive fieldwork with a Navajo family of White Sands focusing on weaving and religious chants. Reichard published this work in the form of two texts - one technical and the other personal. The split between Spider Woman (1934) and Navajo Shepherd and Weaver (1936) points to the tensions, noted by Visweswaran (1988: 32), of a subjective/objective dichotomy prevalent in the writing of ethnography and centered in issues of credibility and gendered definitions of 'scholarly work'. Indeed, Spider Woman is often called an 'autobiographical account' (Lyon, 1989: 138) or a set of 'well-digested field notes, a sort of personal account of the trials of learning to weave interspersed with descriptions of family activities - the summer sheep dip, a trip to the Gallup Ceremonials, a tornado, a sing, and even sadly the death of Maria Antonia...' (Lamphere, 1992:93). Indeed, the relationship between autobiography and ethnology is at the core of a feminist reading of Reichard's narratives. Such a reading applies the approach of taking the personal as political to question the distinction between autobiography, or 'confession', and ethnography. ${ }^{4}$

In her article on the potential for feminist ethnography, Kamala Visweswaran identifies the unique contribution of a number of earlier women anthropologists such as Jean Briggs and Hortense Powdermaker. Critical reviewers of the development of ethnography often relegate these works to a genre of confessional/popular literature. We can situate Reichard firmly within this tradition of women ethnographers writing in a first person or even fictive voice. As Visweswaran notes, 'first person narratives are being selected by women as part of a strategy both of communication and self-discovery' (Visweswaran, 1988: 32). Visweswaran asserts that these women not only pave the way for 'experimental' ethnographies, but also challenge notions of positivist social science. Spider Woman is followed by Dezba, a semi-fictional, thinly-veiled account of the daily life of a Navajo woman and her family. Dezba has been classified as a novel, or as the first biography in Navajo scholarship. However, I see the book as falling squarely within the bounds of ethnography. The events and persons described mirror those of Spider Woman and the time-frame of the book clearly relates to specific stints of fieldwork rather than the plot of a novel. The characters are no more fictionalized than those of many ethnographies seeking to preserve the anonymity of their informants. Nor is it a biography in terms of developing the inner and social life of an individual. The character of Dezba rhetorically unifies descriptions and analysis of a wide range of characters 
and events. Reichard's choice of genre forms a kind of protective cloak for Reichard herself.

We see this cloaking in the way in which Dezba is narrated in a highly detached, stilted, omniscient third person, much like more conventional ethnography of the day. Reichard claims to be writing an intentionally popular account in answer to questions asked by 'laymen, teachers, writers, artists, and tourists whom I have met during many years of sojourn with the Navajo Indians' (Reichard, 1939:v). In addition, she hopes to dispel certain stereotypes of Indians and to illustrate their response to changes instilled by the United States government. One of her primary concerns is the negative effect of boarding schools on Navajo children. She also writes critically of the chaos wrought by other federal policies on the reservation. Reichard's choice of genre hints at her notions about the kinds of audiences anthropologists need to reach (and the authoritative writing to which those audiences may defer) if they are to fulfill their moral and political commitments to those people with whom they work.

Additional evidence of cloaking comes with Reichard's own disguised appearance in the character of a teacher at the end of the narrative. In this section she relates the successes of her (actual) Hogan School, in which she taught Navajo translators to write and read in their own language. I read this as a critique of boarding schools and a testimony to the success of her own adult school, which was shut down through academic and reservation politics (Lyon, 1989).

Reichard may have used fiction as a protective cloak as well as a way to get her side of the story published in a non-academic forum and thus mobilize support. Likewise, the authoritative narrative voice could stand for the objectivity of her evaluation of her Hogan School's success. Reichard faced many trials - including efforts to discredit her scholarship - as a woman ethnographer who was increasingly marginalized by the dominant male anthropologists working on Navajo culture. Reichard was an instructor in anthropology at Barnard, and when her interpretations of Navajo religion conflicted with those of Clyde Kluckhohn and Lee Wyman, she was challenging prominent men in the discipline. They supported each other and countered her with far greater force than she, a single individual, could assert. Academic debates, of course, are not in theory sexist. Having the institutional resources to put into circulation and impose one's views, however, is linked to structural inequities such as gender (Gordon, 1990: 148). The importance of Reichard's work has only recently been recognized. She has been referred to as 'one of the most underestimated of all American anthropologists' (Geertz, 1977: vii). 
In her later work, Reichard turned away from synthesizing interpretations to analysis of specifics, culminating in the two-volume encyclopedic Navajo Religion (1950) in which her writing became increasingly detatched and sterile as Reichard abandoned her more evocative voice and experimented with ethnographic form. Given the dramatic nature of these transformations in Reichard's ethnography, I feel compelled to give a feminist reading to the shifts in genre and voice evidenced in Reichard's career as being intimately linked with the gender politics of the production of knowledge. I use the notion of a feminist 'reading' to avoid forcing a label on Reichard's work which would reflect pure speculation about the author's intentions. However, bringing a feminist perspective to the reading of Reichard's texts allows me to mine them for an understanding of the gender relations both in the field and in the academy.

\section{Reading ethnography for methodology}

I concluded that a study of structure is indispensable for any kind of social study, but that it is by no means enough for the understanding of behavior, attitude, and motivation. . . . I was interested in crafts and decided that learning to weave would be a way of developing the trust of the women, as well as of learning to weave and to speak the language. By this attempt I would put myself under the family aegis; my work would at first deal primarily with women, and I could observe the daily round as a participant, rather than a mere onlooker. ${ }^{5}$

Contemporary anthropologist Helan Page notes that the dialogic process is one in which 'the position of self is assessed in relation to the other's asserted position' (Page, 1988: 165). The dialogic process, then, involves an intense interaction that constitutes the basis for a potentially profound mutual understanding. Thus, this particular understanding is based on a process of what Page terms 'interactive learning'. In this next section, I suggest that we can use Page's discussion of a dialogic methodology based on interactive learning to read Spider Woman for hints of a feminist methodology.

Reichard's approach to fieldwork and the way in which her writing allows us inside that process largely constitutes the strength of Spider Woman as an ethnography. Key aspects of Reichard's methodology included a long-term commitment to the Navajo; the privileging of women's experiences; interactive data gathering; the pursuit of a holistic and thorough understanding of Navajo culture; and developing close, enduring ties with her adoptive family primarily as a 'sister' and a 'grand-daughter'. 
Anthropologist Eleanor Leacock (1988), a student of Reichard's at Barnard, notes that Reichard integrated an understanding of the teaching and learning process into her methodology. We see this emphasis in Reichard's descriptions of her interactions with her weaving instructors:

As I struggle along, learning to control unaccustomed muscles, Marie sits by my side watching carefully lest I make a mistake. We don't talk much, except about the points of the weaving. A child doesn't talk when he is learning to write. Besides, Marie does not 'tell' when teaching. She 'shows.' The Navajo word for 'teach' means 'show' and is absolutely literal. (Reichard, 1934:21)

Reichard's portrayal of her relationships with her teachers demonstrates principles of interactive learning. Through interactive learning, relationships evolve and are enriched over time. The practice of learning involves a kind of relinquishing of authority and a willingness to assume risks:

I take it to show to the women. 'My first blanket is done,' I announce. They are all dying to see it, but as I slowly and tantalizingly unwrap it, I exact the assurance, 'Promise me not to laugh.' They promise. As the stripes held together by some sort of irregular rhythm appear and start across the room they burst with one accord into a chorus of merriment. (Reichard, 1934:49)

One of the strengths of Reichard's study is her effort to push the limits of the ethnographic project by showing that cross-cultural learning - or bridging the 'dialogic gap' (Page, 1988: 166) - is truly possible though challenging:

Marie weaves a great deal on this blanket. Eagerly watching, I feel as she felt when as a little girl she eyed her mother and tried to learn what made the design. She, however, unlike her mother, is not unwilling to help me all she can. She 'shows' me patiently each time I need to advance or to withdraw. The only thing she does not allow me is to make mistakes alone. Take them out if need be, but get understanding I must. However, I finish the day with a feeling of absolute futility. Am I so dull that I cannot grasp this apparently simple point? (Reichard, 1934: 72)

Warm humor often appears in Reichard's interactions with her teachers and certainly in the way in which she writes about herself. This ability to relinquish an authoritative position in interactions as well as in representation constitutes a kind of methodological principle. As she writes,

Marie, arriving early the next morning, finds my hand decorated. I am wearing my favorite blue bandanna folded thickly around my thumb joint and fastened about my wrist with a square knot I achieved with the aid of my teeth. . . . When Maria Antonia comes in, she laughs quietly but mirthfully into her lap, covering her mouth with her hand. She shows me a thick callus on the bone of her thumb. I respect that scar - it is a monument to the scores of beautiful blankets Maria Antonia has woven. And now I know that I am 
not alone in my infirmity. The pain on my own blue-bandaged prominence is less poignant; it has become an honorable scar. I shall try to go forward to the callus ideal. (Reichard, 1934: 24)

The issue of Reichard's positioning of herself in the field brings us to the question of her interaction with the family with whom she lives and studies. Reichard provides an interesting example of different kinds of fictive kin roles available to women anthropologists:

I know that the Navajo are more likely to use relationship terms than names. The circle included by any one of these terms is a large one. Any woman belonging to my clan, whether a blood relation or not, if she is of my generation, is my sister. ... So $\mathrm{I}$, by getting three sisters, secure six delightful children. Marie and I talk over all this. She knows enough of white people to realize how amusing the system is, but she is pleased about it, as are the others. (Reichard, 1934: 35-36)

This passage reminds us that anthropologists enter into a whole range of relationships and roles which are constantly negotiated. Of course, some relations receive priority. In Reichard's case, it is interesting to note that she is nobody's daughter but rather, primarily, a grand-daughter and a sister. ${ }^{6}$ While this relates to Navajo notions of proper kin roles, I think it also reflects the fact that Reichard remains relatively autonomous from the family - she lives in a separate abode, doesn't share in the chores, and comes and goes as she pleases.

Reichard uses the goal of learning to weave to establish her position in the family, but from this position she gains a vantage on many aspects of Navajo life. So while learning about weaving from the women, she also studies sacred healing practices with her grandfather who is a chanter of great renown. Reichard depicts the ways in which her relations with the family are continually negotiated. For example, Reichard's Navajo grandfather performs a healing ritual for one of the sisters, but Reichard's participation in this family activity must be negotiated:

But now to my dismay he orders me out. I do not know if I am to be left out permanently or only temporarily, and my chagrin overpowers my hopes as I loiter alone like a naughty child outside at the back of the hogan. Almost at once, to my relief, Tom hunts me up, explaining apologetically: 'The old man says you could come in all right, but he don't think you want to. You see, they are all going to undress.' 'But I don't mind that as long as there are no white people,' I protest. 'Your women all do it - why can't I?' (Reichard, 1934: 156)

Reichard participates in the ceremony, but only after facing questions of gender and ethnicity in this cross-cultural encounter. As in the above example, bridges can be built across the dialogic gap - that disparity between world-views, power and resources which makes communication 
difficult. Yet Reichard reminds us throughout her study that the ethnographer can never assume that those gaps can be permanently smoothed over.

On a more critical note, I would like to raise some methodological issues which emerge when Reichard works with Navajo with whom she establishes neither permanent nor profound links. After gaining a degree of proficiency in weaving (over the course of several summers), Reichard travels around investigating different weaving styles and natural dyes. She makes a short-term contract with one family with whom she shares no other affinity. The husband of her teacher constantly questions her project:

'This kind of weaving is hard. Not many women know how to do it. You ought, therefore, to pay my wife a large sum for having her teach you.' I point out that, while teaching me, she is getting more than any of the educated girls who are working, and at the same time she can be working for herself. I try to be patient as I explain these things. These people live near the railroad. They have been exploited for years by white people. They are on the defensive against exploitation but they really have no defense. 'You will learn to weave, and you will teach the white women to weave so that the Navajo women won't be able to earn any more.'

Reichard tells him how slow she is at weaving and how bad she is at spinning. Still, he demands both greater compensation and explanation:

I tell him I make a point of never to pay before a job is done. As soon as the blanket comes down, I will pay his wife for it, just as the trader would if she brought it to the post ...

Luckily for me, Kinni's-Son is not home every day. . . . His wife seems to like having me there. . . . When I pay her the first time, her son tells me 'she is glad.' My surmise, corroborated by white observers and other Navajo, is that Kinni's-Son is supported largely by the industry of his women, and he wants to be supported as well as possible. (Reichard, 1934: 216-217)

I find the last remark particularly disturbing. Does Reichard use her concern for the exploitation of Navajo women by their husbands to justify her own extractive practices? This scene, in which relations between Reichard and the Navajo are stripped bare of personal ties of affection, makes me question her relations with her own Navajo family. Reichard's work exemplifies the contrast between intense, long-term methods of elucidating social relations and extensive surveys focusing on cultural artifacts. We need to ask how such different styles of fieldwork relate to the politics and production of knowledge.

\section{Concluding thoughts: weaving as feminist practice}

Spider Woman instructed the Navajo women how to weave on a loom which Spider Man told them how to make. The crosspoles were made of sky and 
earth cords, the warp sticks of sun rays, the healds of rock crystal and sheet lightning. The batten was a sun halo, white shell made the comb. There were four spindles: one a stick of zigzag lightning with a whorl of cannel coal; one stick of flash lightning with a whorl of turquoise; a third had a stick of sheet lightning with a whorl of abalone; a rain streamer formed the stick of the fourth, and its whorl was white shell. (Navajo Legend) ${ }^{7}$

I have left virtually unexamined the most obvious metaphor in Reichard's work - weaving. Weaving illustrates Reichard's convictions about the importance of Navajo aesthetics, the centrality of women in Navajo social fabric and a holistic approach to the study of culture. In addition, weaving illuminates Reichard's understanding of the ethnographic process itself.

As discussed above, learning to weave provides both Reichard and the reader with a seemingly less obtrusive vantage point on the social life and beliefs of the Navajo. Yet we should remember that Reichard also pursues Navajo weaving as a specific object of analysis. Reichard makes her mark in a specialized field - the study of Navajo weaving - populated by six male anthropologists. Matthews, Uriah S. Hollister, Pepper, James and Charles Avery Amsden, ${ }^{8}$ preceded her, each doing what he considered a comprehensive study. They, as men, almost necessarily wrote as observers of this feminine craft, and their writings have the weakness, the omissions, of the by-stander's version of what happened.

Reichard's choice of weaving as a focus of her work raises questions about the way in which she positioned herself in an academic arena dominated by men. Perhaps she saw this project as a way of using her grasp of gender relations (and their extension to a division of labor) to carve a space for herself both in the field and the academy. Though she may have used her gender in a way which played upon essentialized notions of 'feminine crafts', this does not mean that she herself viewed gender as a fixed category (or that women can only best study women). We could also see Reichard's positioning as an attempt to break with the detached, hierarchical field relations which may have been established by her male predecessors. ${ }^{9}$ These points indicate the need to situate Reichard's work within the politics of anthropological research of the time. In addition, we can look at Reichard's pursuit of weaving more sympathetically as indicative of more general processes of cross-cultural fieldwork. Having mastered the basic skills under the supervision of Maria Antonia's family, Reichard sets off to investigate unusual patterns and natural dyes by visiting other weavers. Having collected samples, Reichard returns to teach these techniques to the weavers of Maria Antonia's family. Like most ethnographers of her day, Reichard utilized techniques of data 
collection based on personal relationships with a small group or monetary contracts with a series of key informants.

Ethnographers tend to move from localized sites of analysis to pull in broad interpretations of an entire culture. Reichard, as privileged outsider, masters and then transcends her locus of analysis to compile a broader understanding unavailable to any single individual within the culture. Thus, in Reichard's work, the process of learning to weave exemplifies her general approach to the project of anthropological research. I find this metaphor of fieldwork as weaving compelling. It conveys a careful, meticulous recognition of the centrality of process in crafting ethnography as well as the importance of the aesthetic appeal of the finished product.

On a more critical note, Spider Woman ends with a scene between Reichard and her weaving instructors which raises a set of issues that persist throughout her account - the question of whether cross-cultural learning is truly possible, the risks of losing control over that which is taught, and the relationship between the ethnographer and the people with whom she works:

I am weaving the 'double-faced' when Djiba's-Mother comes to see us. She remarks to Marie, 'She is beating us.' 'No,' I reply, 'if you were weaving the same thing yours would be more even, and your edge would be better. I just know the way to do it, you know how to make a good blanket.' To Marie I add, 'That is always the way with a good teacher; she learns from her pupils.' (Reichard, 1934:286)

Reichard's Navajo instructors congratulate themselves that they were indeed able to teach a white woman to weave and again express their concern that, with this knowledge, white women will take over their work as weavers. Reichard's assurances and their own experiences in unsuccessfully teaching other white women convince the Navajo weavers that no white woman, even Reichard, has the patience or quickness to compete. Although for Reichard this ending resolves certain tensions, I feel that she has been somewhat naive. After all, to the white traders, the value of Navajo rugs has less to do with their aesthetic merit or perfection of craft, and more to do with their status as artifacts of an exotic, primitive people. Furthermore, though Reichard attributes white women's reluctance to weave to a lack of patience, we should note that the differential value of white and Navajo women's labor plays a key role in the economy of weaving. I have to wonder about the connections between the study of Navajo weaving, the maintenance of anthropological subjects and economic relations on the reservation. 
Reichard recognizes that Navajo chanters (men) place the highest value on knowledge. Indeed, she willingly pays for access to that knowledge and expresses her awareness of the dangers of possible misuse of those sacred materials. Yet Reichard seems to regard the knowledge of learning to weave differently:

When Kinni's-Son sees my progress, he is amazed and baffled. He starts on his long speech of fear about white competition. He has been driven by my speed in learning to the following peroration: 'This is hard to learn. Not many persons know how to do this kind of weaving. It took my wife a long time to learn it. You have learned it so quick you ought to pay her five dollars a day instead of five dollars a week for teaching you.' (Reichard, 1934: 218)

While Reichard generally conveys an awareness of her emotional ties and commitments to the people she studies, this passage raises disturbing issues. Reichard fails to analyze the political and structural relations between herself and the Navajo women. That Reichard does not explicitly recognize the full value - especially for her own purposes - of the knowledge held by Navajo weavers, is a central contradiction in her work.

Ultimately, Reichard denies the connection between the economy of Navajo weavings and the academic market for knowledge of exotic customs and cultures. These tensions of appropriation demonstrate the dangers of the intimacy of ethnographic research - and, I would add, feminist critique - that contemporary sociologist Judith Stacey calls to our attention: 'Ethnographic method exposes subjects to far greater danger and exploitation than do more positivist, abstract, and "masculinist" research methods. The greater the intimacy, the apparent mutuality of the researcher/researched relationship, the greater is the danger' (Stacey, 1988: 24). ${ }^{10}$ Nevertheless, Stacey also emphasizes the strengths of a feminist ethnography as a methodology for women learning about other women in an interactive process:

Like a good deal of feminism, ethnography emphasizes the experiential. Its approach to knowledge is contextual and interpersonal, attentive like most women, therefore, to the concrete realm of everyday reality and human agency. Moreover, because in ethnographic studies the researcher herself is the primary medium, the 'instrument' of research, this methodology draws on those resources of empathy, connection, and concern. (Stacey, 1988: 22)

Whether or not we classify Reichard as a feminist ethnographer matters less to me than understanding that it is this aspect of ethnography the representation of a dialogic process - to which Reichard is most 
attuned. Even some male colleagues of her time perceive this as key to her work. As a colleague of her era wrote,

Dr Reichard, a woman, first of all learned to weave, then wrote about it as a weaver. We have long known how Navaho weaving looks; now, thanks to her, we know how it feels. She writes of the labor, the errors and frustrations and minor triumphs that lie behind the finished product on which her male predecessors fixed their admiring eyes. (Amsden, 1938: 725)

It was the above passage that helped me to see that weaving could be a key to understanding what ethnography meant to Reichard. In Reichard's early writings, the process of fieldwork is as important as the product or final ethnographic text. In this sense, Reichard imbued weaving with the concerns and care due to a master craft:

The outlining means additional work, but is very typical of Navajo weaving. When Atlnaba made the small blanket with the comb pattern for me, she picked up and dropped thirty different weft threads in weaving a single row across the middle. A good weaver of course never considers how much work a pattern is. She sees it as a finished whole and exerts herself to accomplish the ideal. (Reichard, 1934: 112)

In Reichard's writings, if due care was taken in the process then the final text would have even edges, and would integrate the various and complex threads of a culture into a work with aesthetic integrity. Yet this type of wholeness does not necessarily imply closure. Rather, Reichard crafts an ethnography that includes its own contradictions and challenges, while depicting her own growth as a person engaged in cross-cultural learning. Reichard's writing involves us, as readers, in the process of interactive learning as she creates an ethnography which engages and entrances. Reichard offers an example to the contemporary feminist reader of how to enact a feminist practice in which learning and teaching become the key forms for the production of new ethnographic knowledge.

\section{ACKNOWLEDGMENTS}

I would like to thank Laura Ahearn, Ruth Behar, Crisca Bierwert, Janet Finn, Catherine Lutz, Mark Somoza and the members of the Women Writing Culture Seminar for their insightful comments. The editors of Critique of Anthropology also provided helpful comments. Unfortunately, I am not able to pursue their bibliographic suggestions as I am revising from 'the field'. Ruth Behar introduced me to the work of Gladys Reichard and provided inspiration and direction throughout the Women 
Writing Culture Project. This paper was written under the support of a National Science Foundation Training Grant.

\section{NOTES}

1. Mary Louise Pratt (1986) discusses at length the romanticizing conventions of the ethnographic arrival scene. Reichard is clearly writing what Johannes Fabian in Time and the Other (1983) would call 'coeval' ethnography.

2. Lamphere provides a rich and indispensable account of Reichard's life and works. For a detailed evaluation of Reichard's relationship with other scholars of the Southwest, see Lyon (1989).

3. On the tensions between Reichard and Ruth Benedict, see Modell (1983:167,221,258). Curiously, Benedict's other biographer, Margaret $M$. Caffrey (1989: 102-112, 273-274), puts little emphasis on the conflict between the two scholars.

4. Barbara Tedlock (1991) has insightfully suggested that Spider Woman follows the plot line of a novel of education.

5. From A New Look at the Navajo, Reichard, n.d. cited in: Lamphere (1989: 91).

6. On the ethnographer as 'daughter' see contributions by Laura Ahearn and Susan Walton to the Women Writing Culture Conference (Ann Arbor, 1991).

7. Appears on the title page of Spider Woman.

8. See Hollister (1903) and Charles Avery Amsden (1934).

9. Mary Louise Pratt (1986) raises a similar issue in noting the dilemmas faced by Marjorie Shostak as she situated herself within a tradition of anthropological studies among the !Kung.

10. I don't necesarily agree with Stacey's classification of methods by gender. However, her assertions are not incompatible with the claim that experimental ethnography has been seen as the purview of contemporany male anthropologists, precisely because few of these recent 'experiments' has given methodological issues serious consideration.

\section{REFERENCES}

Amsden, Charles Avery (1934)

Navajo Weaving, Its Technique and History. Santa Ana: Fine Arts Press.

Amsden, Charles (1938)

'Book Review: Navajo Shepherd and Weaver', American Anthropologist 40: 724. Caffrey, Margaret M. (1989)

Ruth Benedict: Stranger In This Land. Austin: University of Texas Press.

Deacon, Desley (1992)

'The Republic of the Spirit: Fieldwork in Elsie Clews Parsons's Turn to Anthropology', Frontiers 12(3): 13-38. 
Fabian, Johannes (1983)

Time and the Other: How Anthropology Makes its Object. New York: Columbia University Press.

Geertz, Clifford (1977)

'Foreword', in Gary Witherspoon, Language and Art in the Navajo Universe. Ann Arbor: University of Michigan Press.

Gordon, Deborah (1990)

'The Politics of Ethnographic Authority: Race and Writing in the Ethnography of Margaret Mead and Zora Neale Hurston', in Marc Manganaro (ed.) Modernist Anthropology: From Fieldwork to Text. Princeton: Princeton University Press.

Harding, Sandra, ed. (1987)

Feminism and Methodology. Bloomington: Indiana University Press.

Hollister, Uriah S. (1903)

The Navajo and his Blanket. Denver.

Lamphere, Louise (1989)

'Feminist Anthropology: The Legacy of Elsie Clews Parsons', American Ethnologist 16(3): 518-533.

Lamphere, Louise (1992)

'Gladys Reichard among the Navajo', Frontiers 12(3) 79-115.

Leacock, Eleanor (1988)

'Gladys Amanda Reichard', in Ute Gacs, Aisha Khan, Jerrie Mcintyre and Ruth Weinberg (eds) Women Anthropologists: A Biographical Dictionary. New York: Greenwood Press.

Lyon, William H. (1989)

'Gladys Reichard at the Frontiers of Navajo Culture', The American Indian Quarterly 13: 137-163.

Modell, Judith Schachter (1983)

Ruth Benedict: Patterns of a Life. Philadelphia: University of Pennsylvania Press.

Page, Helán E. (1988)

'Dialogic Principles of Interactive Learning in the Ethnographic Relationship', Journal of Anthropological Research 44(2): 163-181.

Pratt, Mary Louise (1986)

'Fieldword in Common Places', in James Clifford and George E. Marcus (eds) Writing Culture: The Poetics and Politics of Ethnography. Berkeley: University of California Press.

Reichard, Gladys Amanda (1928)

Social Life of the Navajo Indians. New York: Columbia University Press.

Reichard, Gladys Amanda (1934)

Spider Woman. New York: Macmillan.

Reichard, Gladys Amanda (1936)

Navajo Shepherd and Weaver. New York: J.J. Augustin.

Reichard, Gladys Amanda (1939)

Dezba, Woman of the Desert. New York: J.J. Augustin.

Reichard, Gladys Amanda (1950)

Navajo Religion: A Study in Symbolism, 2 vols. New York: Pantheon. 
Stacey, Judith (1988)

'Can There Be a Feminist Ethnography?' Women's Studies International Forum 11(1): $21-27$.

Tedlock, Barbara (1991)

'From Participant Observation to the Observation of Participation: The Emergence of Narrative Ethnography', Journal of Anthropological Research 47(1): 73.

Visweswaran, Kamala (1988)

'Defining Feminist Ethnography', Inscriptions 3/4: 32.

Witherspoon, Gary (1977)

Language and Art in the Navajo Universe. Ann Arbor: University of Michigan Press. 